\title{
DAUR ULANG SAMPAH PLASTIK SEBAGAI MITIGASI PERUBAHAN IKLIM
}

\author{
Eka Nada Shofa Alkhajar 1), Agusniar Rizka Luthfia ${ }^{2)}$ \\ ${ }^{1,2}$ Fakultas Ilmu Sosial dan Ilmu Politik, Universitas Sebelas Maret, Surakarta \\ Email: ${ }^{1}$ ekanadashofa@staff.uns.ac.id
}

\begin{abstract}
Abstrak
Perubahan iklim adalah sebuah persoalan global yang dihadapi seluruh umat manusia. Orangorang perlu mengetahui bagaimana cara menghadapi perubahan iklim. Secara umum, ada dua strategi utama untuk mengurangi resiko dari dampak perubahan iklim. Salah satunya adalah mitigasi perubahan iklim. Strategi ini terdiri dari upaya-upaya untuk mengurangi atau mencegah peningkatan emisi gas rumah kaca. Dalam konteks ini, remaja pun memiliki peran penting untuk ambil bagian dan melakukan aksi nyata. Salah satu bentuk aksi nyata tersebut adalah dengan mendaur ulang sampah plastik. Sampah plastik adalah salah satu sumber emisi gas rumah kaca. Oleh karena itu, aksi ini sangatlah penting untuk dilakukan. Kegiatan pengabdian kepada masyarakat ini bertujuan untuk membekali remaja keterampilan untuk mendaur ulang sampah plastik terutama botol plastik bekas. Hasil yang dicapai dari kegiatan pengabdian kepada masyarakat ini adalah mitra kegiatan telah memiliki keterampilan untuk mendaur ulang sampah plastik menjadi benda-benda yang menarik dan bernilai guna.
\end{abstract}

Kata Kunci: mitigasi, perubahan iklim, remaja, sampah plastik

\begin{abstract}
Climate change is a global problem faced by all mankind around the world. People need to know how to address climate change. In general, there are two main strategies to reduce the risk of climate change impacts. One of them is climate change mitigation. The strategy consists of all efforts to reduce or prevent the escalation of greenhouse gas emissions. In this context, teenagers have an important role to take a part and do a real action. One of the forms is by recycling plactic waste. Plastic waste is one of the sources of greenhouse gas emissions. Therefore, it is very important to do such action. This community devotion aims to equip teenagers an ability to recycle plastic waste especially bottle plactic waste. The result achieved from this community devotion is that the target of community devotion has an ability to recycle plastic waste into interesting and useful items.
\end{abstract}

Keywords: mitigation, climate change, teenagers, plastic waste

\section{PENDAHULUAN}

Sampah plastik di Indonesia merupakan sebuah persoalan yang serius. Sebuah riset, misalnya, menyatakan Indonesia berada pada posisi kedua dari 192 negara yang diteliti sebagai penyumbang sampah plastik di lautan. Sementara itu, posisi pertama ditempati Tiongkok. Sedangkan
Filipina, Vietnam dan Sri Lanka secara berurutan masuk mengisi daftar lima besar negara penyumbang sampah plastik di lautan dalam hasil riset tersebut (Jambeck et al., 2015). Hasil riset Jambeck et al. ini tentu bukan kabar baik bagi Indonesia.

Beberapa pihak di Indonesia bahkan menyanggah hasil riset tersebut. Pemerintah 
Indonesia melalui Kementerian Lingkungan Hidup dan Kehutanan, misalnya, mengatakan hasil riset itu tak akurat karena tidak merepresentasikan kondisi riil di Indonesia. Meskipun demikian, hasil riset tersebut setidaknya dapat menjadi alarm penting bagi kita semua bahwa sampah plastik adalah sebuah persoalan serius yang harus segera dicarikan solusinya. Ini dimaksudkan agar sampah plastik tidak semakin memberi dampak negatif terhadap lingkungan dan makhluk hidup.

Sebagaimana diketahui, sampah plastik adalah salah satu sumber emisi gas rumah kaca yang mana sangat berpengaruh terhadap terjadinya perubahan iklim. Bahkan plastik itu sendiri sejak awal proses produksinya telah mengemisikan banyak gas rumah kaca. Kondisi ini masih diperparah dengan banyaknya orang yang belum sadar akan bahaya sampah plastik. Sebagian besar orang bahkan tidak peduli, acuh tak acuh dan tak mau tahu akan persoalan sampah plastik tersebut. Padahal sampah plastik jelas bukan persoalan yang sederhana. Indonesia bahkan sudah memasuki apa yang disebut sebagai darurat sampah plastik. Berkenaan dengan hal ini, pemerintah Indonesia sendiri memang tidak tinggal diam dan melakukan berbagai aksi dengan target untuk mengurangi sampah plastik.

Pemerintah melakukan hal tersebut karena pengurangan sampah plastik berkaitan erat dengan pengurangan resiko dari dampak perubahan iklim. Secara garis besar terdapat dua strategi besar untuk merespon, menghadapi dan mengurangi resiko perubahan iklim. Salah satunya adalah mitigasi perubahan iklim.

Strategi ini terdiri dari upaya-upaya yang dilaksanakan untuk mencegah dan mengurangi peningkatan emisi gas rumah kaca. Salah satu bentuk aksi mitigasi perubahan iklim adalah mendaur ulang sampah plastik. Seperti diketahui, remaja adalah kelompok potensial untuk ikut berkontribusi di dalam aksi mitigasi perubahan iklim. Meskipun demikian, perlu diketahui pula bahwa remaja merupakan salah satu fase dalam kehidupan manusia yang ditandai dengan kondisi transisi dari fase anak-anak ke fase dewasa (Santrock, 2010; Shaffer dan Kipp, 2010; Santrock, 2013). Fase ini adalah masa yang kritis dan penuh pergolakan sehingga sangat penting untuk memastikan remaja senantiasa berada di jalur yang positif dan tidak terjebak ke dalam jalur negatif seperti kenakalan remaja, narkoba dan lain sebagainya (Alkhajar, 2007; Luthfia et al., 2019a).

Untuk itu, remaja perlu dilibatkan dalam aksi mitigasi perubahan iklim di mana hal ini juga merupakan upaya menjaga mereka agar berada di jalur yang positif dan bermanfaat. Remaja harus senantiasa disadarkan akan peran-peran strategis yang mereka miliki. Apalagi mereka adalah generasi muda dan generasi penerus bangsa (Alkhajar, 2014; Luthfia et al., 2019b). Sebagaimana telah disinggung sebelumnya, salah satu contoh peran strategis yang dapat dilakukan adalah ikut berperan aktif dalam aksi mitigasi perubahan iklim yang mulai dari lingkungan sekitar mereka (Giddens, 2009).

Oleh karena itu, potensi besar dari remaja ini harus dapat dioptimalkan agar remaja menjadi bagian dari solusi persoalan. Berdasarkan uraian tersebut, kegiatan pengabdian kepada masyarakat (PKM) ini dimaksudkan untuk membekali mitra kegiatan kemampuan dan keterampilan untuk mendaur ulang sampah plastik sebagai salah satu bentuk aksi mitigasi perubahan iklim.

\section{METODE PELAKSANAAN}

Metode yang digunakan pada kegiatan PKM ini adalah ceramah dan pendampingan. Metode ceramah dipakai untuk menjelaskan cara dan teknik dalam mendaur ulang, mengolah serta menghias sampah plastik menjadi aneka produk kerajinan tangan yang bisa digunakan oleh para remaja. Kemudian metode pendampingan digunakan saat para remaja mendaur ulang sampah plastik berupa botol-botol plastik bekas.

Jumlah peserta yang mengikuti kegiatan adalah 30 peserta. Kegiatan pengabdian ini merupakan tindak lanjut dari kegiatan yang diselenggarakan pada 29 Desember 2018 berkaitan dengan edukasi dan 
literasi perubahan iklim di kalangan remaja. Kegiatan ini adalah bentuk aplikasi dan praktik mitigasi perubahan iklim dengan mendaur ulang sampah plastik berupa botolbotol plastik bekas menjadi produk-produk kerajinan tangan yang menarik dan bernilai guna.

\section{HASIL DAN PEMBAHASAN}

Seperti telah disebutkan sebelumnya, kegiatan PKM ini merupakan kelanjutan dari kegiatan yang diselenggarakan dan ditujukan kepada mitra kegiatan yakni kelompok remaja Masjid Al-Fatah yang berada di Dukuh Trowangsan, Desa Malangjiwan, Kecamatan Colomadu, Kabupaten Karanganyar.

Dengan kata lain, setelah sebelumnya mereka mendapatkan input materi mengenai literasi perubahan iklim mereka kemudian didampingi dan dibekali keterampilan untuk dapat berkontribusi dan melakukan aksi nyata. Aksi nyata ini tak lain adalah praktik mitigasi perubahan iklim dengan mendaur ulang sampah plastik berupa botol-botol plastik bekas.

Hal ini dimaksudkan agar mitra kegiatan dapat ikut berperan dalam upaya mereduksi sampah plastik secara mandiri dengan tangan mereka sendiri dan dimulai dari lingkungan di sekitar mereka sendiri. Dengan mereduksi sampah plastik artinya kita telah ikut berperan dalam mengurangi emisi gas rumah kaca.

Sebelumnya, pelaksana dan mitra kegiatan sama-sama membawa bahan utama berupa botol-botol plastik bekas dan kain bekas yang akan digunakan untuk keperluan daur ulang dan hiasan. Adapun pelaksanaan kegiatan ini dimulai dengan ceramah mengenai cara dan teknik mendaur ulang botol-botol plastik bekas. Informasi ini berguna agar mitra kegiatan memiliki gambaran awal cara dan teknik mendaur ulang maupun menghias botol-botol plastik bekas tersebut.

Setelah itu, mitra kegiatan didampingi untuk praktik daur ulang. Kegiatan ini dimulai dengan beberapa langkah. Pertama, memotong botol-botol plastik bekas tersebut menjadi beberapa bentuk. Kedua, mempercantiknya dengan menggunakan cat berwarna-warni. Ketiga, memperindahnya dengan anyaman kain bekas, tempelan kulit kerang dan bahan lainnya.

Ketika melaksanakan sesi praktik ini mitra kegiatan terlihat sangat antusias dan bersemangat. Hal ini dapat dengan jelas terlihat pada dokumentasi kegiatan.

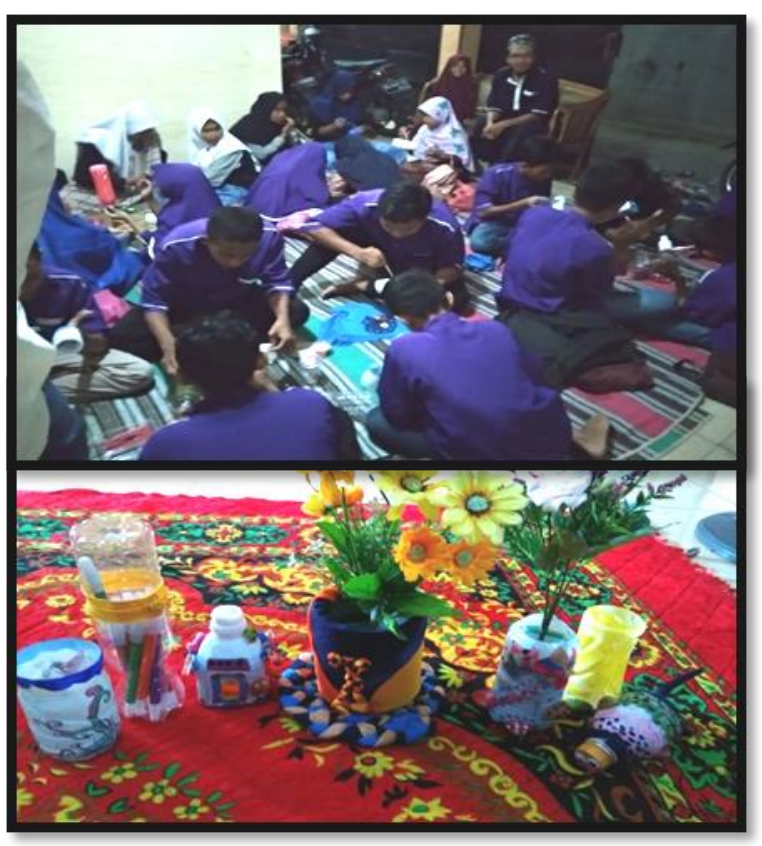

Gambar 1. Dokumentasi Kegiatan

Kemudian pada dokumentasi kegiatan tersebut dapat pula terlihat pembimbing mitra kegiatan yakni Bapak Budi Santoso yang tengah memperhatikan kelompok remaja binaannya dengan seksama. Adapun produkproduk kerajinan yang dihasilkan dari daur ulang botol plastik bekas ini antara lain adalah wadah alat tulis dan vas bunga yang menarik. Selain itu, mitra kegiatan juga bisa menggunakan botol plastik bekas yang telah didaur ulang sebagai pot tanaman di rumah masing-masing.

Di akhir kegiatan, para peserta mengatakan bahwa kini mereka menjadi semakin memahami arti penting dari mitigasi perubahan iklim. Dan mereka pun semakin menyadari bahwa aksi mitigasi perubahan iklim dapat dimulai dari hal sederhana yang ada di sekitar mereka. Melalui kegiatan ini pula mereka semakin menyadari peran 
penting dan tanggung jawab mereka untuk ikut serta menjaga lingkungan agar tetap lestari (Luthfia and Alkhajar, 2018).

\section{KESIMPULAN}

Aksi mitigasi perubahan iklim perlu dilakukan semua pihak termasuk para remaja sebagai generasi muda. Salah satu aksi yang dapat dilakukan adalah mendaur ulang atau mengkreasi sampah plastik berupa botol plastik bekas menjadi berbagai benda yang bernilai guna. Dengan adanya kegiatan ini, para peserta telah mendapatkan pengetahuan berupa cara dan teknik kreatif untuk mendaur ulang sampah plastik.

Secara keseluruhan kegiatan PKM ini berjalan dengan baik dan lancar. Seluruh peserta juga sangat antusias mengikuti jalannya kegiatan. Tak hanya itu, mereka pun memberikan apresiasi dan respon yang sangat positif. Mereka mengatakan bahwa kegiatan ini sangat berguna bagi mereka sebagai generasi muda untuk semakin peduli terhadap lingkungan khususnya berkaitan dengan perubahan iklim.

\section{REFERENSI}

Alkhajar, Eka Nada Shofa. 2007. Hiperrealitas dalam Kehidupan Nyata. Kompas, 31 Desember.

Alkhajar, Eka Nada Shofa. 2014. Media, Masyarakat dan Realitas Sosial. Surakarta: Sebelas Maret University Press.

Giddens, Anthony. 2009. The Politics of Climate Change. Cambridge: Polity Press.

Jambeck, Jenna R., Roland Geyer, Chris Wilcox, Theodore R. Sieger, Miriam Perryman, Anthony Andrady, ramabu Narayan, and Kara Lavender Law. 2015. Plastic Waste Inputs from Land into the Ocean. Science, 347(6223): 768-771.

Luthfia, Agusniar Rizka and Eka Nada Shofa Alkhajar. 2018. Strengthening Public Awareness on Climate Change: Lesson learned from a youth social movement in Yogyakarta, Indonesia. IOP Conference Series: Earth and
Environmental Science, Vol. 200, 012033. DOI : $10.1088 / 1755-$ 1315/200/1/012033

Luthfia, Agusniar Rizka, Eka Nada Shofa Alkhajar, Desiderius Priyo Sudibyo, Son Haji, dan Wahyu Nurharjadmo. 2019a. Penulisan Fiksi Sebagai Wahana Artikulasi Gagasan Generasi Muda. Bakti Cendana, 2(2): 66-70.

Luthfia, Agusniar Rizka, Nurhayatu Nufut Alimin, Febriani Sarwendah Asri Nugraheni dan Eka Nada Shofa Alkhajar. 2019b. Penguatan Literasi Perubahan Ikilm di Kalangan Remaja. Abadimas Adi Buana, 3(1): 39-42.

Santrock, John W. 2010. Adolescence. New York: McGraw-Hill.

Santrock, John W. 2013. Life-span Development. New York: McGrawHill.

Shaffer, David R. and Katherine Kipp. 2010. Development Psychology: Childhood and Adolescence. 8th Ed. Belmont, CA: Wadsworth, Cengage Learning. 